\title{
Mandibular Permanent Second Molar Impaction Treatment options and outcome
}

\author{
Nir Shpack ${ }^{1}$, Tamar Finkelstein ${ }^{1}$,Yon H. Lai ${ }^{2}$, Mladen M. Kuftinec ${ }^{2}$, Alexander Vardimon ${ }^{1}$, \\ Yehoshua Shapira ${ }^{1, *}$ \\ ${ }^{1}$ Department of Orthodontics, The Maurice and Gabriela Goldschleger School of Dental Medicine, Tel Aviv University, Israel \\ ${ }^{2}$ Department of Orthodontics, New York University College of Dentistry, New York \\ *Corresponding Author: yehoshua.shapira@gmail.com
}

Copyright (C) 2013 Horizon Research Publishing All rights reserved.

\begin{abstract}
To determine the prevalence of mandibular second molar impaction in orthodontic patients of two ethnic groups, present treatment options and discuss their outcome. 6500 panoramic radiographs of orthodontically treated patients (3500 Israeli and 3000 of Chinese-American origin) aged 11-15 years were examined for mandibular second molar impactions. 120 patients with 165 impacted mandibular second molars were identified, presenting a prevalence of $1.8 \%$. Many ( $88 \%$ ) were mesially angulated. Impactions were more prevalent in the Chinese-American group than in the Israeli group (59\% and $41 \%$, respectively). Sequential treatment options are presented and discussed, and the outcomes of several treatments are presented. A prevalence of $1.8 \%$ for MM2 impactions was detected in our sample. Clinicians should be aware of the possible impaction of mandibular permanent second molars. Early detection and initiating of orthodontic intervention directed toward correction of the impaction are recommended for best clinical results and long-term prognosis.
\end{abstract}

Keywords Impaction, Mandibular Second Molar, Molar Uprighting

\section{Introduction}

Impaction of a permanent tooth is a relatively common clinical occurrence that may involve any tooth in the human dentition. Most commonly it involves the mandibular and maxillary third molars, the maxillary canines or central incisors and the mandibular second premolars [1,2]. A tooth is impacted when it fails to erupt due to an obstacle such as the presence of a supernumerary tooth or an odontoma, lack of adequate space in the arch, an abnormal eruption path, or with no apparent etiology (idiopatic) [3].

Impaction of the mandibular permanent second molars (MM2) are not very common and their prevalence studied either clinically or by inspection of panoramic radiographs has been reported to be $0.03 \%$ of the general population [4] and $2-3 \%$ of orthodontic patients $[5,6]$. MM2 impaction is found more often in males, occurs more frequently unilaterally and is present more commonly on the right side [5]. MM2 may be impacted in three forms of angulation : mesially or distally inclined and vertically positioned (Fig. $1 \mathrm{~A} \& \mathrm{1B})$. They are found most commonly mesially inclined with their long axis more than 30 degrees mesially inclined relative to the first molar $[6,7]$.
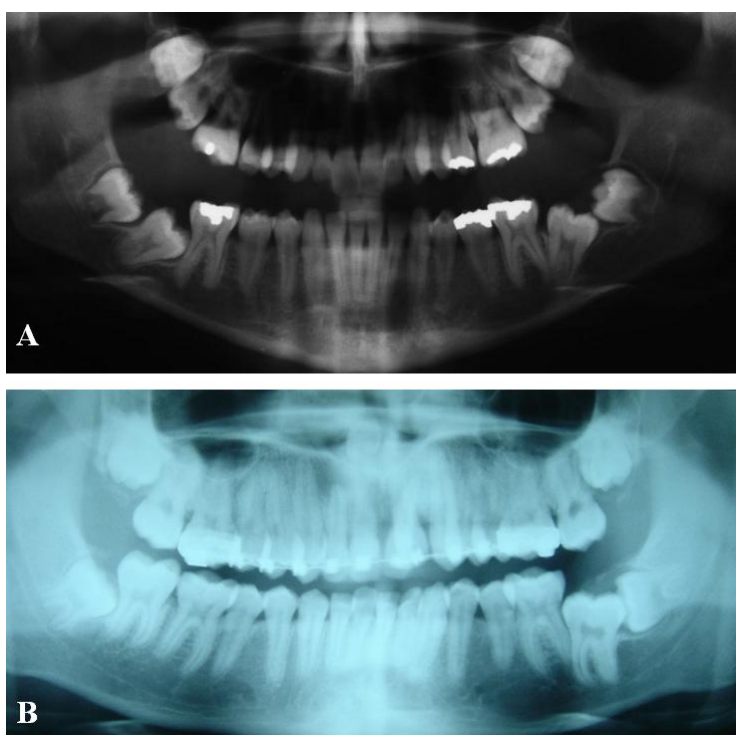

Figure 1. A Mesially angulated right impacted MM2. Distally angulated left impacted MM2. B Vertically positioned impacted left MM2

MM2 impaction is often detected in a routine panoramic radiograph during pedodontic or orthodontic evaluation and treatment planning and is usually not the main reason for referral to the orthodontist. Early detection and treatment is imperative to avoid a possible external root resorption of the first molar [6, 8], caries and periodontal involvement of the first and second molars and pricoronal inflammation [3]. This may eliminate the need for complicated orthodontic and surgical treatment.

Several treatment approaches and orthodontic techniques have been suggested in the literature to correct this 
abnormality. These included some challenging treatment options of surgical repositioning [9-12], as well as orthodontic uprighting and traction into their correct position in the arch [13-16].

The purpose of the present paper was to evaluate the prevalence of MM2 impaction, to present and discuss both surgical treatment options and orthodontic techniques and assess their outcome.

\section{Materials and Methods}

Our sample consisted of selected panoramic radiographs of 6500 consecutively treated orthodontic patients (3500 Israelis and 3000 Chinese-Americans). Age group was 11-15 years (mean age 12.8 years) with no significant difference in patient's age between the two groups.

Selected criteria for MM2 impaction was:

Complete eruption of the MM2 on one side, whereas the contralateral tooth has not emerged

The second molar was mesially angulated with its mesial cusps located below the distal undercut of the first molar.

\section{Results}

A total of 120 patients (49 Israelis and 71 Chinese-Americans) had 165 impacted mandibular second molars, presenting a prevalence of $1.8 \%$.

The distribution included 75 unilateral and 90 bilateral impacted teeth, 53\% were found in males and $47 \%$ in females. A great majority of them $(88 \%)$ were mesially angulated. $8 \%$ were vertically positioned and only $4 \%$ had distal angulation.

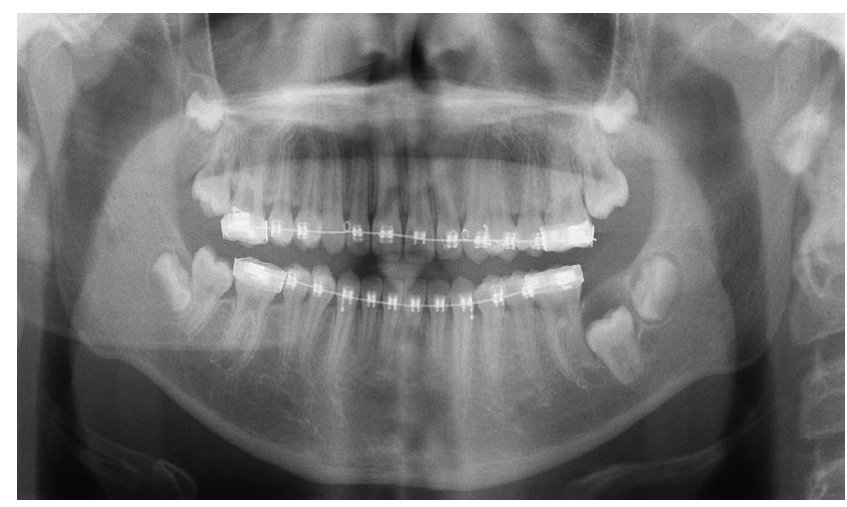

Figure 2. A follicular cyst on top of left MM2 causing its impaction.

Our sample included some bizarre impactions of the mandibular second molars. A follicular cyst around the crown of a mandibular left second molar, detected in an 11 years old girl causing its impaction, was surgically removed and the tooth was later exposed and brought into occlusion via orthodontic traction (Fig. 2). A rare and abnormal bucco-lingual position of bilaterally impacted second molars was detected in a 17 years old male of a Chinese-American origin who was referred for orthodontic treatment. His two impacted teeth were surgically removed allowing the developing third molars to erupt and migrate mesially, were then uprighted and brought into position to replace the second molars (Fig. 3).

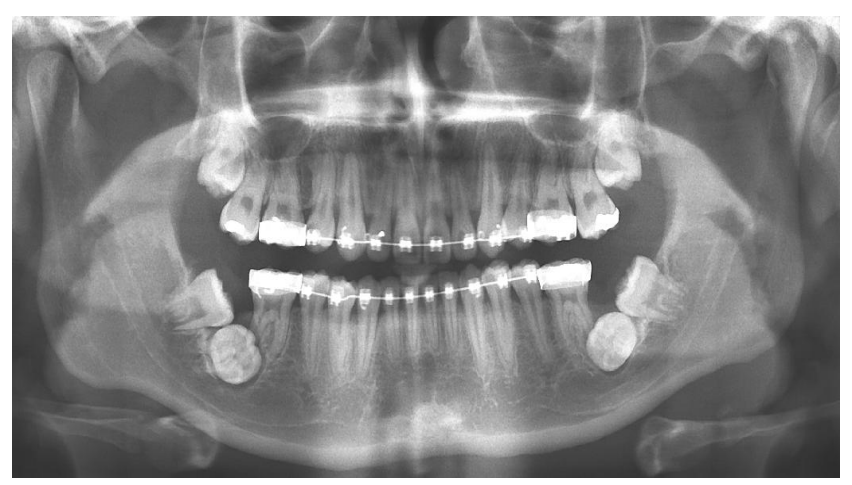

Figure 3. Bilateral impaction of MM2's in bucco-lingual angulation

An unusual case with a horizontally impacted left mandibular second molar and a fully developed impacted third molar lying on top of the second molar was detected in a 22 years old male referred for orthodontic treatment. The third molar was extracted, following exposure of the second molar's crown, bonding an eyelet and using a direct Temporary Anchorage Device (TAD) in the anterior border of the ramus for uprighting and traction into occlusion (Fig. 4 $\mathrm{A}, \mathrm{B}, \mathrm{C})$.
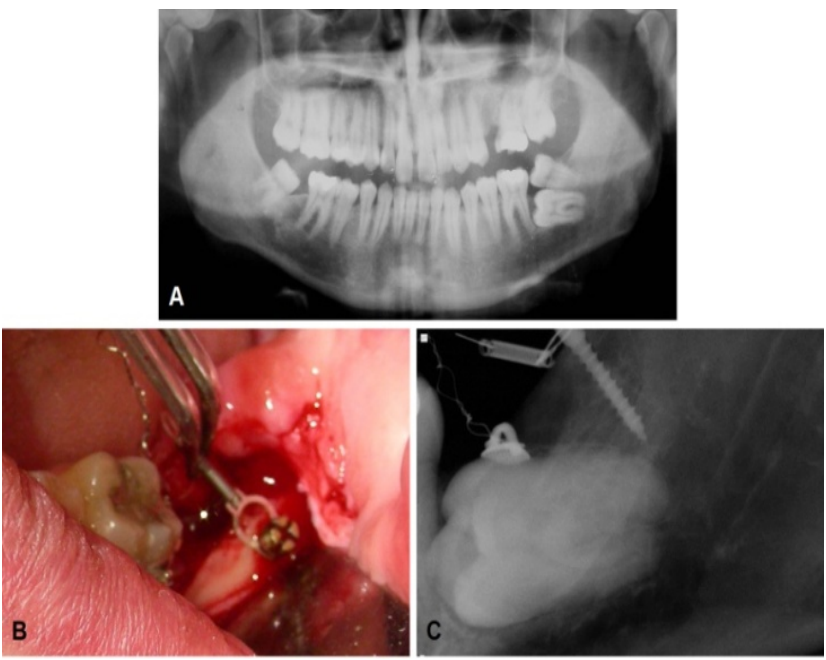

B\&C A Temporary Anchorage Device (TAD) in the anterior border of the ramus for uprighting and traction into occlusion

Figure 4. A horizontally impacted left MM2 and a fully developed impacted third molar lying on top of it (with permission of Dr. Naomi Bechor).

Occasionally, the erupting second molar may be arrested under the disto-gingival edge of the first molar band (Fig.5 A \& B), or a stainless steel crown (Fig. 6) causing its mesial angulation and impaction. Replacing the molar band with a bonded tube will often allow for the eruption of the second molar. 

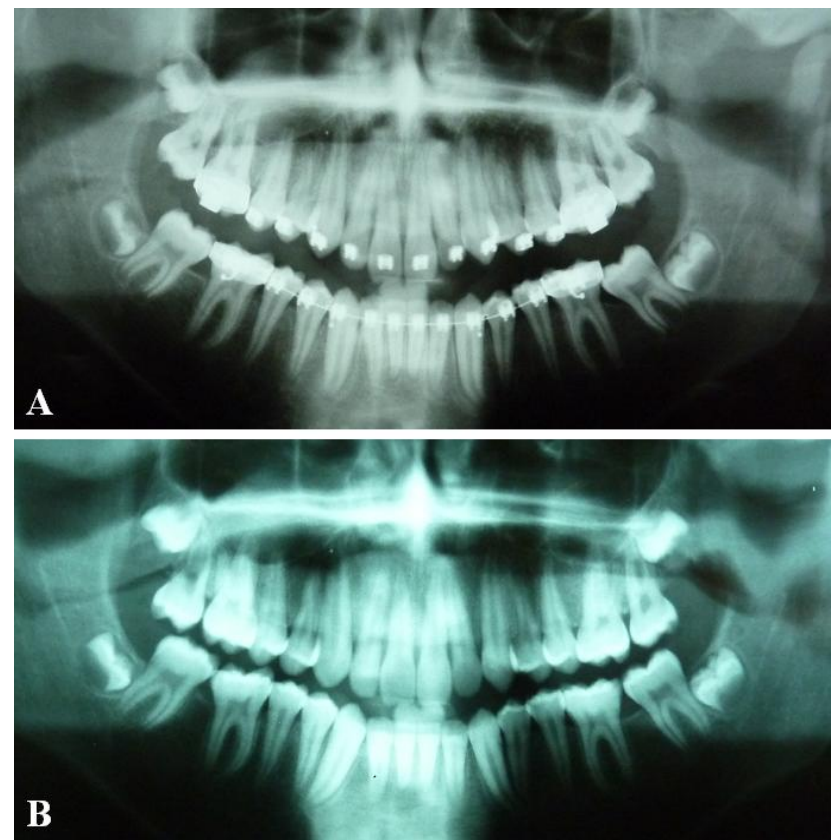

B Left MM2 aligned in the arch following removal of the first molar band. Figure 5. A Left MM2 arrested under the disto-gingival edge of the first molar band causing its mesial angulation and impaction.

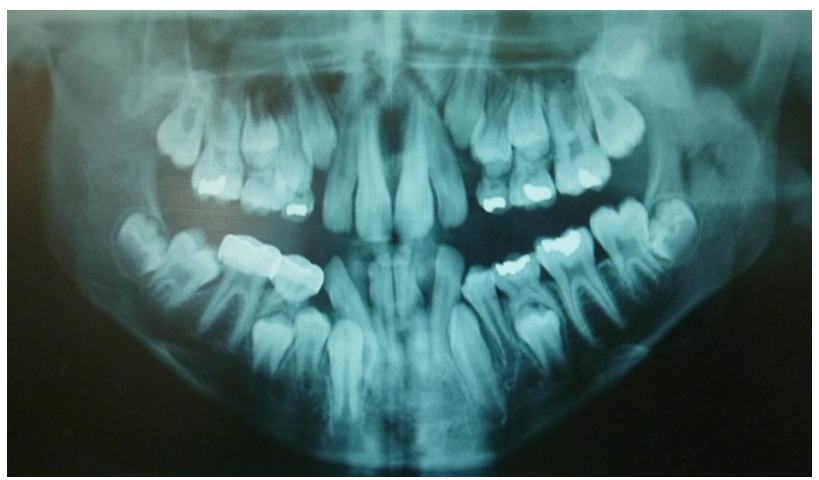

Figure 6. Right second molar arrested under the disto-gingival edge of the first molar stainless steel crown.

Surgical uprighting and repositioning of the impacted second molar is a relatively quick procedure, particularly when patient compliance is minimal. This can be achieved with or without the removal of the adjacent third molar, though removal of the third molar will make the procedure easier (Fig. 7 A-F). When the surgically uprighted tooth is not stable, it should be rigidly stabilized for few weeks.

A .Pretreatment panoramic radiograph. B Third molar extracted. C Second molar surgically uprighted. D Second molar stabilized with sutures. E Second molar in the arch. F Posttreatment panoramic radiograph
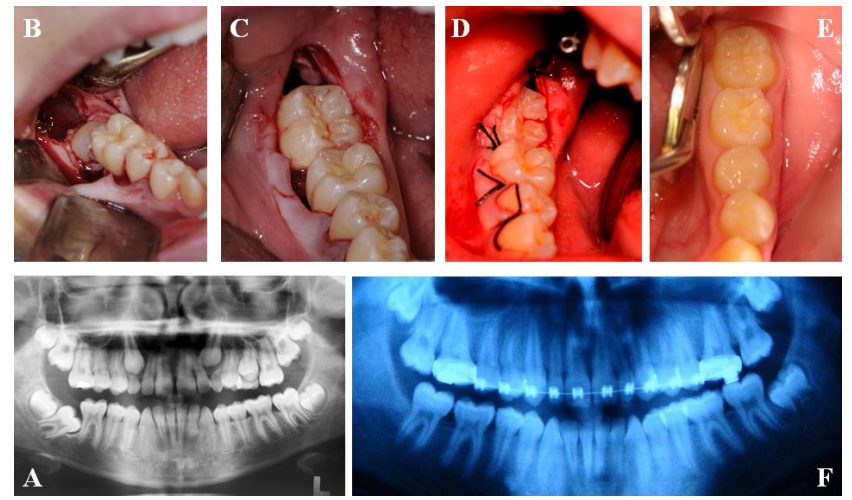

Figure 7. Surgically uprighting of an impacted right mandibular second molar (with permission of Dr. Eyal Tarazi):

Conventional orthodontic methods for uprighting impacted mandibular second molar is often the best alternative to extraction or surgically repositioning of the tooth. This treatment approach can be performed with or without extraction of the adjacent third molar. It requires surgical exposure and uncovering the crown, followed by bonding an orthodontic attachment for uprighting and erupting of the tooth (Fig. 8 A-G).
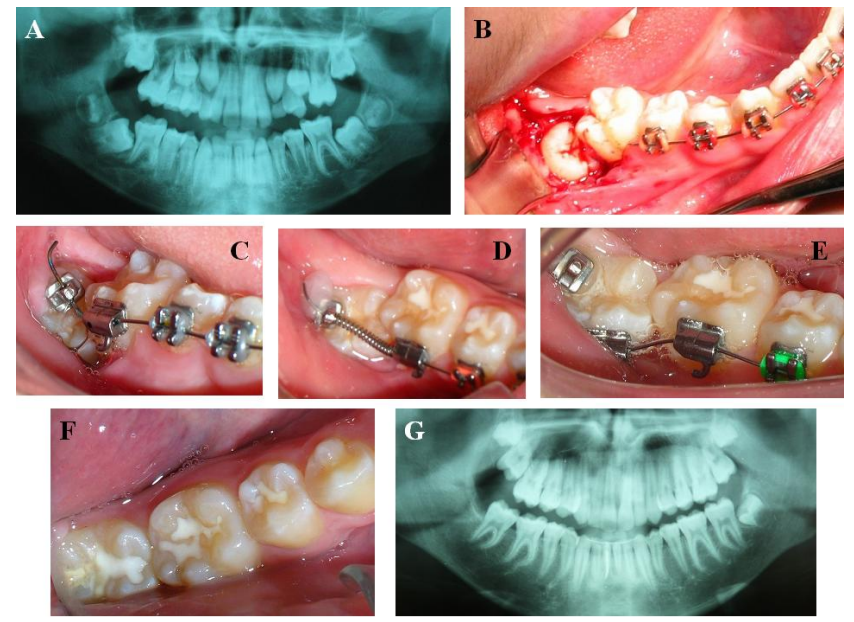

Figure 8. Orthodontic uprighting of an impacted right mandibular second molar: A Pretreatment panoramic radiograph. B Surgical extraction of third molar bud and exposure of the impacted second molar. $\mathrm{C}$ Bonded eyelet on disto-occlusal crown edge of the impacted molar with a NiTi wire to upright the tooth. D Push coil spring to distalize the second molar. E Buccal tube on the buccal surface of the second molar with a NiTi wire. F Second molar aligned in the arch. G Posttreatment panoramic radiograph.

An uprighting spring attached to a bonded tube on the disto-buccal cusps of the second molar is a simple way to upright the angulated and impacted tooth (Fig. 9 A-C). 

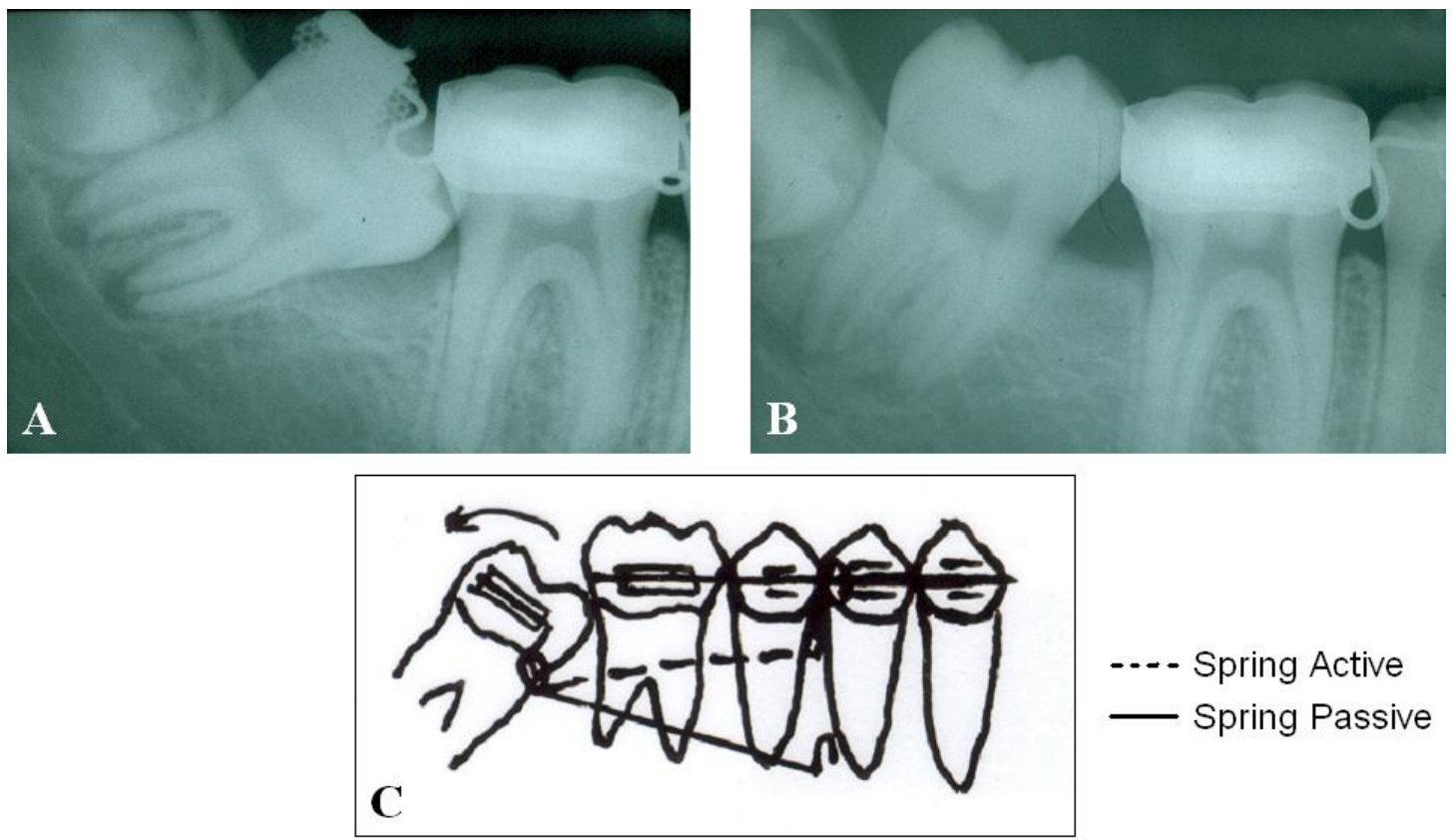

Figure 9. Simple uprighting spring: A Tube bonded on the disto-buccal cusp of the impacted second molar. B Second molar is uprighted. C Diagram of an uprighting spring.

\section{Discussion}

Early diagnosis and early treatment are the keys for successful correction of mandibular second molar impaction. Management of such teeth is considered very difficult, unpredictable and is a challenge both to the orthodontist and oral surgeon. Close collaboration between the two specialists is imperative for the successful outcome.

The suggested age group to treat these impactions is between 11 and 14 years when second molar roots formation is not completed and before the third molar completes its development above and on top of the second molar. The erupting mandibular second premolar and second molar may quite often compete for space in the posterior region of the arch. When this space is inadequate the earlier erupting second premolar may result in the impaction of the second molar. Resisting mesial movement of the first molars during the transitional dentition is a major cause of mesially impacted second molars, because the local anatomy demands some degree of first molar mesial migration. This has an important impact on certain treatment modalities, for instance the extended use of lip bumpers. In addition, the developing third molar may also compete for space behind and above the second molar, resulting in its impaction [7]. The great majority of mandibular second molar impaction $(88 \%)$ was found together with a degree of mesial angulation [6]. This can be radiographically seen as an oblique or even horizontal position of the tooth, and it could be a result of the initial mesial inclination of the developing bud of the second molar. This is in contrast to the unerupted mandibular second premolar, which has been reported to develop with distal inclination $[17,18]$.

A very rare case of an inverted impacted second molar where its crown was directed towards the lower border of the mandible has been previously reported [19]. Our sample also included some bizarre impactions of the mandibular second molars. One was caused by a follicular cyst around the crown of a mandibular left second molar in an 11 years old girl (Fig. 2 ), which was removed surgically allowing the eruption of the second molar. A second one was a result of an abnormal bucco-lingual position of bilaterally impacted second molars detected in a 17 years old male (Fig. 3). Surgical removal of the two bucco-lingual impacted teeth allowed the developing third molars to erupt and migrate mesially, were then uprighted and brought into position to replace the second molars (Fig. 3).

An unusual case with a horizontally impacted left mandibular second molar and a fully developed impacted third molar lying on top of the second molar was detected in a 22 years old male referred for orthodontic treatment. The third molar was extracted, following exposure of the second molar's crown, bonding an eyelet and using a direct temporary anchorage device (TAD) in the anterior border of the ramus for uprighting and traction into occlusion (Fig. 4 $\mathrm{A}, \mathrm{B}, \mathrm{C})$.

Treatment options for resolution of the impacted mandibular second molar include:

1. When a second molar is only slightly mesially angulated, a separating elastic, brass ligature wire or spring separator ( De-Impactor) between the first and second molars often relieve the tight contacts between the teeth allowing "self-correction" and its eruption.

2. Occasionally, the erupting second molar may be arrested under the disto-gingival edge of the first molar band (Fig.5 A \& B), or a stainless steel crown (Fig. 6) causing its mesial angulation and impaction. 
Replacing the molar band with a bonded tube will often allow for the eruption of the second molar.

3. Surgical extraction of an impacted mandibular second molar that have no chance of uprighting due to its extremely unfavorable position (Fig. 3). This will allow the developing third molar to erupt into the second molar space. Such a procedure is quite risky and the oral surgeon must be very careful not to injure the adjacent teeth. In addition, the positional development and eruption path of the third molar is unpredictable, it may tip mesially and become impacted. As a result, the tooth would have to be exposed, uprighted and brought into the arch. Extraction of the third molar is unfavorable as it will end up in a short occlusal table with only one mandibular molar. Moreover, with time, over eruption of its antagonist is expected, resulting in occlusal interferences.

4. Surgical uprighting and repositioning of the impacted second molar is a relatively quick procedure, particularly when patient compliance is minimal. This can be achieved with or without the removal of the adjacent third molar, though removal of the third molar will make the procedure easier. The outcome of this procedure is presented in Fig. 7 A-F. This procedure should be done by an experienced oral surgeon as it may risk the adjacent teeth, resulting in fracture of the uprighted tooth, loss of its vitality, root resorption and ankylosis [9-11]. When the surgically uprighted tooth is not stable, it should be rigidly stabilized for few weeks. Splinting the surgically uprighted tooth with autogenous bone graft has also been suggested [12].

5. The impacted second molar can be surgically extracted and immediately transplanted into its socket, or transplantation of the third molar to the second molar socket has also been suggested [20,21]. This is a risky procedure as the transplanted tooth may be lost due to infection, become ankylosed and the roots are subject to resorption.

6. Conventional orthodontic methods of uprighting is often the best alternative to extraction or surgically repositioning of the impacted mandibular second molar. This treatment approach can be performed with or without extraction of the adjacent third molar. It requires surgical exposure and uncovering the crown, followed by bonding an orthodontic attachment for uprighting and erupting of the tooth. For that purpose several techniques and appliances have been suggested. These include:

A A bonded attachment on the occlusal surface or to the disto-buccal area of the second molar with an auxiliary spring fixed in a vertical lingual sheath $[22,23,24]$, a push coil spring [25], or superelastic NiTi wire to upright and move the tooth distally. The nice outcome of this technique is presented in Fig. 8 A-G.
B A bonded tube on the disto-buccal cusps (Fig. 9 A \& B), or to the buccal surface of the impacted second molar with an uprighting spring $[13,26]$ is a relatively simple procedure to upright and align the impacted tooth.

C A TAD inserted in the retromolar area using elastic chain, or NiTi coil spring attached from the TAD to the attachment on the tooth will pull it distally to upright it. The TAD may also be inserted into the buccal alveolar bone on the mesial side of the first molar, using a push coil spring to upright and distalize the impacted second molar [27].

D Inter-arch vertical elastics [28] and a removable appliance with an uprighting spring [29] were also suggested for initial uprighting of the mandibular impacted second molar.

\section{Conclusion}

A prevalence of $1.8 \%$ was found for MM2 impaction in orthodontically treated patients. Orthodontic techniques have a significant advantage of uprighting the impacted tooth without need of surgical procedure, bone removal or splinting.

A successful outcome of mandibular second molar impaction therapy that offers better long-term prognosis depends on early diagnosis and initiating adequate treatment for surgical exposure and orthodontic uprighting techniques.

\section{Acknowledgements}

The author would like to thank Mr. Amir Shapira for his valuable help in the preparation of this article, and to Dr. Naomi Bechor and Dr. Eyal Tarazi for the use of their clinical photographs.

\section{REFERENCES}

[1] Aitasalo K, Lehtinen R, Oksala E. An orthopantomographic study of prevalence of impacted teeth. Int J Oral Surg. 1972; 1:117-120.

[2] Kramer RM, Williams AC. The incidence of impacted teeth. Oral Surg. 1970; 29:237-241.

[3] Raghoebar GM, Boering G, Vissink A, Stegenga B. Eruption disturbances of permanent molars: a review. J Oral Pathol Med. 1991; 20;159-166.

[4] Grover PS, Norton L. The incidence of unerupted permanent teeth and related clinical cases. Oral Surg Oral Med Oral Path. 1985; 59:420-425.

[5] Varpio M, Wellfelt B. Disturbed eruption of the lower second molar: clinical appearance, prevalence and etiology. J Dent Child. 1988; 55:114-118. 
[6] Shapira Y, Finkelstein T, Shpack N, Lai YH, Kuftinec MM, Vardimon A. Mandibular second molar impaction Part I: Genetic trait and characteristics. Am J Orthod Dentofac Orthop. 2011;140:32-37.

[7] Wellfelt B. Varpio M. Disturbed eruption of the permanent lower second molar: treatment and results. J Dent Child. 1988; 55:183-189.

[8] Sawicka M, Racka-Pilszak B, Rosnowska-Mazurkiewiez M. Uprighting partially impacrted permanent second molars . Angle Orthod. 2007; 77:148-154.

[9] Peskin S, Graber TM. Surgical repositioning of teeth. J Am Dent Assoc. 1970; 80:1320-1326.

[10] Johnson JV, Quirk GD. Surgical repositioning of impacted second molar teeth. Am J Orthod Dentofac Orthop. 1987; 91:242-251.

[11] Pogrel MA. The surgical uprighting of mandibular second molars. Am J Orthod Dentofac Orthop. 1995; 108:180-183.

[12] Davis WH, Patakas BM, Kaminishi RM, Parsch NE. Surgically uprighting and grafting mandibular second molars. Am J Orthod Dentofac Orthop. 1976; 69:555-561.

[13] Shapira Y, Borell G, Nahlieli O, Kuftinec MM. Uprighting mesially impacted mandibular second molars. Angle Orthod 1998; 68:173-178.

[14] Majourau A, Norton LA. Uprighting impacted second molars with segmented springs. AM J Orthod Dentofac Orthop. 1995; 107:235-238.

[15] Eckhart JE. Orthodontic uprighting of horizontally impacted mandibular second molar. J Clin Orthod. 1998; 32:621-624.

[16] Ferrazzini G. Uprighting of a deeply impacted mandibular second molar. Am J Orthod Dentofac Orthop 1989; 96:168-171.

[17] Bjorlin G, Lundgren K. Migrating nonerupted lower bicuspids. Odont Revy 1975;26:145-148.
[18] Shalish M, Chaushu S, Wasserstein A. Malposition of unerupted mandibular second premolar in children with palatally displaced canines. Angle Orthod 2009; 79: 796-799.

[19] Ferandes HA. Unerupted inverted mandibular second molar. Case report J All India Dent assoc. 1965; 37:269.

[20] Apfel H. Transplantation of the unerupred third molar tooth. J Oral Surg. 1956; 9:96.

[21] Symposium: transplantation, reimplantation and surgical positioning of teeth. Oral surg Oral Med Oral Path. 1956; 9:3-122;125-192.

[22] Ferrazzini G. Uprighting of a deeply impacted mandibular second molar. Am J Orthod Dentofac Orthop 1989; 96:168-171.

[23] Johnson E, Taylor RC. A surgical orthodontic approach in uprighting mandibular second molars. Am J Orthod 1972; 61:508-514.

[24] Rubin RM. Uprighting impacted molars. J Clin Orthod 1977; $11: 44-46$

[25] Freeman RS. Mandibular second molar problems. Am J Orthod Dentofac Orthop 1988; 94:19-21.

[26] 26.Orton HS, Jones SP. Correction of mesially impacted lower second and third molars. J Clin Orthod 1987; 21:176-181.

[27] Lee KJ, Park YC, Hwang WS, Seong EH. Uprighting mandibular second Molars with direct mini screw anchorage. J Clin Orthod 2007;41:627-635.

[28] Gazit E, Lieberman M. A mesially impacted mandibular second molar. Treatment considerations and outcome: A case report. Am J Orthod Dentofac Orthop 1993; 103:374-376

[29] Henns RJ. Uprighting impacted mandibular second molars. Angle Orthod 1975; 45:314-316. 